\section{Case-Control Study Comparing the Relationship between Pain, Neurobehavioral Functioning and a History of Playing Professional Contact Sports}

\section{Nadir Haider ${ }^{1}$, Daniel Antonius ${ }^{2}$, Adam Cunningham ${ }^{1}$, Erik J Radick², Raphael J Leo'2, Matthew D Scalco ${ }^{3}$, Brian Zachariah², Ross D Zafonte ${ }^{4}$, John J Leddy ${ }^{1}$ and Barry S Willer ${ }^{2 *}$}

${ }^{1}$ Department of Orthopaedics, Jacobs School of Medicine and Biomedical Sciences, Buffalo, USA

${ }^{2}$ Department of Psychiatry, Jacobs School of Medicine and Biomedical Sciences, Buffalo, USA

${ }^{3}$ Department of Psychology, University of New Orleans, New Orleans, USA

${ }^{4}$ Department of Physical Medicine and Rehabilitation; Harvard Medical School, Boston, USA

\begin{abstract}
Objective: Chronic pain is known to affect neurocognitive functioning; retired professional athletes are at high risk of having chronic musculoskeletal pain. However, this relationship has not been investigated in retired professional contact sport athletes who are suspected to have early neurocognitive decline due to repetitive head injuries during their careers.

Participants: Twenty-one retired National Football League and National Hockey League players (Contact Sport, CS) and 21 agematched non-contact sport athletic controls (Non-contact Sport, NS).

Design: Case-control

Main measures: Behavior Regulatory Index (BRI) and Metacognitive Index (MI) from Behavioral Rating Inventory of Executive Function-Adult, anxiety from Beck Anxiety Index, depression from Beck Depression Inventory-II, and Pain Intensity and Interference from Patient Reported Outcome Measure Information System-43.
\end{abstract}

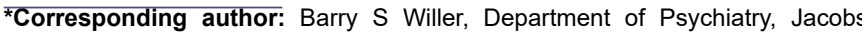
School of Medicine and Biomedical Sciences, State University of New York at Buffalo, Buffalo, New York, USA, Tel: (716) 829-2300; E-mail: bswiller@buffalo. edu

Citation: Haider MN, Antonius D, Cunningham A, Radick EJ, Leo RJ, et al. (2021) Case-Control Study Comparing the Relationship between Pain, Neurobehavioral Functioning and a History of Playing Professional Contact Sports. J Alzheimers Neurodegener Dis 7: 058.

Received: October 26, 2021; Accepted: October 29, 2021; Published: November 05, 2021

Copyright: () 2021 Haider MN, et al. This is an open-access article distributed under the terms of the Creative Commons Attribution License, which permits unrestricted use, distribution, and reproduction in any medium, provided the original author and source are credited.
Results: CS group reported significantly more pain intensity and interference $(p<0.001)$ than NS. On exploratory binary logistic regressions, body mass index $(p=0.039)$, pain interference $(p=0.014)$, and anxiety $(p=0.010)$ were significant predictors of BRI. Pain interference $(p=0.002)$ was the sole significant predictor of MI. A history of playing contact sports was significant for neither.

Conclusion: Our results suggest there may be important causes of early neurocognitive decline in this population other than just a history of playing contact sports.

Keywords: Chronic traumatic encephalopathy; Traumatic encephalopathy syndrome; Retired athlete; NFL; NHL; Pain; Concussion

\section{Introduction}

Mood disorders and cognitive deficits are major concerns among retired contact sport athletes [1]. Studies utilizing post-mortem brain autopsies have shown that $80 \%$ to $99 \%$ of contact sport athletes, mainly former National Football League (NFL) and National Hockey League (NHL) players, have observable tau deposition characteristic of Chronic Traumatic Encephalopathy (CTE) [2-4]. These deceased contact sport athletes also demonstrated a pervasive pattern of impairment in overall cognition, executive functioning, affective lability, and behavior (impulsivity) prior to death that some have hypothesized is a direct consequence of repetitive head injuries received during their professional careers [5]. This pattern of behavior in the living has been termed Traumatic Encephalopathy Syndrome (TES). Studies utilizing next-of-kin interviews of deceased contact sport athletes have also described a consistent pattern of neurobehavioral impairments [6,7]. However, studies utilizing intensive neurocognitive assessments in living contact sport athletes report conflicting results, with limited evidence for early neurodegeneration. Several studies have found few differences on a full range of cognitive assessments and on critical cognitive factors between retired contact sports athletes and controls $[8,9]$. Importantly, mean neurocognitive test scores on almost every measure of cognition were in the average range for age [9] and there were no differences in mental health [10] or incidence of Mild Cognitive Impairment [11] (MCI, the precursor of dementia) between retired contact sport athletes and non-control sport controls.

Although a history of repetitive head injuries during contact sports has been identified as a possible cause of early cognitive decline in retired contact athletes, other potential causes of early decline in this population include obesity [12,13], sleep apnea [14], depression [15], cardiovascular disease [14], anxiety [15], reduced cognitive reserve [7], and decreased physical activity [16]. Another factor that has not yet been studied is the effect of chronic pain on cognition and behavior in this population. Chronic pain is a considerable cause for concern among professional contact sport athletes as they typically suffer from many acute and persistent musculoskeletal injuries over the course of their careers $[17,18]$. High levels of pain in athletes have been linked to prior or recurrent injuries and/or multiple surgeries $[19,20]$. A systematic review [21] has identified chronic pain to be significantly associated with abnormalities in neurobehavioral functioning (i.e., deficits in memory, processing speed, and attention) and 
Citation: Haider MN, Antonius D, Cunningham A, Radick EJ, Leo RJ, et al. (2021) Case-Control Study Comparing the Relationship between Pain, Neurobehavioral Functioning and a History of Playing Professional Contact Sports. J Alzheimers Neurodegener Dis 7: 058.

is associated with brain atrophy and chronic neuroinflammation. It has also been shown that higher levels of chronic pain are strongly correlated with psychiatric manifestations such as anxiety and depression [22].

The vast majority of pain research has focused on the experience and/or intensity of chronic pain in retired contact sport athletes. Some studies, however, have examined the impact of pain on daily activities, which is called "pain interference". These studies reveal that pain intensity interacts with pain interference synergistically to affect activities of daily living, work, exercise, and sleep [23,24]. The primary aim of this study was to compare pain intensity and pain interference between contact sport retired professional athletes and matched non-contact sport athletes. The secondary aim was to compare the relationship of neurobehavioral functioning with a priori identified causes of early decline, including pain intensity/interference, history of playing contact sports, age, education, obesity, anxiety, and depression. We hypothesized that contact sport athletes would have significantly more pain intensity and pain interference than age-matched, non-contact sport athlete controls, and that pain would be significantly associated with neurobehavioral functioning.

\section{Methods}

This prospective case control study was approved by the State University of New york at Buffalo IRB. Participants were invited to participate in the study and consent was obtained after eligibility was determined. Participants completed a questionnaire about their demographics, medical history, had a musculoskeletal physical exam, performed a battery of neurobehavioral questionnaires, and were assessed by an experienced neuropsychologist who diagnosed them with or without MCI based on Comprehensive Criteria [25]. Detailed MCI results are presented in a previous paper [11]. As part of the larger Healthy Ageing Mind project [26], participants also completed additional questionnaires and had a brain MRI.

\section{Participants}

Retired professional contact sport athletes (CS) were contacted and recruited through NFL and NHL alumni associations. Interested participants voluntarily contacted the research center, and if meeting inclusion/exclusion criteria, they were enrolled. Criteria for inclusion included (1) played a professional contact sport for two or more seasons of exposure; (2) currently retired from competitive sports; and (3) between 36-72 years of age. Criteria for exclusion included (1) unwilling or medically unable to receive an MRI; (2) sustained a concussion within the past two years; (3) history of moderate to severe brain injury due to other causes such as assault or vehicular accident; (4) history of cerebrovascular event that could lead to hypoxia; and (5) history of a learning disability. Additional details about recruitment and possible bias are discussed in the limitations section of the Discussion.

Non-contact sport controls (NS) were recruited by contacting running, swimming and cycling athletic clubs with rosters that included older athletes. Our recruiting method ensured that all non-contact sport controls were actively involved in some form of regular exercise at the time of recruitment. Inclusion criteria were (1) athletes who participated in local or national competitive, individual, non-contact sports such as running, cycling, or swimming when they were younger; (2) currently retired from competitive sports; (3) between 36-72 years of age; and (4) no history of self-reported or documented concussions. Exclusion criteria were the same as the retired professional contact-sport athlete group. Additional details about recruitment and possible bias are discussed in the limitations section of the Discussion.

\section{Outcome measures}

Behavior rating inventory of executive function-adult (BRIEF-A) [27]: The BRIEF-A is a 75-item questionnaire for adults aged 18-90 years comprised of a self-report form and an informant-report form. We used the self-report scale, which assesses various factors of executive functioning including inhibition, self-monitoring, planning/ organizing, set shifting, initiating, task monitoring, emotional control, working memory and organization of materials, yielding an overall composite measure of Global Executive Functioning (GEF). Answers are scored from 1 (never a problem) to 7 (always a problem) and higher total scores indicate poorer executive function. Two composite domain scores were obtained: (1) Behavior Regulation Index (BRI, inhibit, shift, control, and monitor) and (2) Metacognitive Index (MI, initiate, working memory, plan/organize, task monitor, and organization of materials). Raw scores are converted to T-scores and rated as abnormal or normal according to the scoring manual.

Patient reported outcome measure information system (PROMIS-43) [28]: The PROMIS-43 is a non-disease specific instrument that assists in measurement of health outcomes. This instrument contains 43 items covering seven total domains that encompass physical and mental health: physical function, anxiety, depression, fatigue, sleep disturbance, satisfaction with participation in social roles, and pain interference (the experience of pain interfering with daily activities). Each of these subscales/domains consists of six items scored from 1 to 5 , with higher scores indicating greater severity. Additionally, there is one pain intensity item that rates the experience of pain from 1 to 10 , with higher scores indicating pain that is more problematic. For the purpose of this study, only pain interference and pain intensity were used in the analysis.

Beck depression inventory-II (BDI-II) [29]: The BDI-II is a validated 21-item self-report psychometric questionnaire, where each question has corresponding answers that can be rated from 0 to 3 with total scores ranging from 0 to 63 . A total score of $\leq 13$ indicates minimal risk for depression whereas 14 and higher is associated with mild to severe depression. The Cronbach's alpha for the BDI-II is 0.92 , indicating high-to-excellent internal consistency.

Beck anxiety inventory (BAI) [30]: The BAI is a validated 21-item self-report psychometric questionnaire where each question has corresponding answers rated from 0 to 3 with total scores ranging from 0 to 63 . A total score of $\leq 7$ indicates minimal risk for anxiety whereas 8 and higher is consistent with mild to severe anxiety. The Cronbach's alpha for the BAI is 0.89-0.94, indicating high-to-excellent internal consistency.

\section{Statistical Analysis}

No sample size calculation was done for this preliminary study. A series of non-parametric $t$-tests and $\chi^{2}$-tests were used to assess differences between CS and NS for continuous [age, body mass index (BMI), BDI-II raw, BAI raw, pain intensity and interference, BRIEF-A composite scores] and categorical [ethnicity, education (college degree: yes/no), diagnosis of MCI, history of smoking, alcohol abuse and drug abuse, abnormal BDI-II and BAI, abnormal $\mathrm{BRI}$ and $\mathrm{MI}$ ] variables, respectively. Data from both groups were combined and binary logistic regression was used to predict the 
Citation: Haider MN, Antonius D, Cunningham A, Radick EJ, Leo RJ, et al. (2021) Case-Control Study Comparing the Relationship between Pain, Neurobehavioral Functioning and a History of Playing Professional Contact Sports. J Alzheimers Neurodegener Dis 7: 058.

dependent variable (BRI and MI) with the following independent variables: history of playing contact sports (binary), age (years, continuous), education (college degree, binary), BMI ( $\mathrm{kg} / \mathrm{m}^{2}$, continuous), BDI-II (binary), BAI (binary), pain intensity ( $\max =10$, continuous), and pain interference ( $\max =30$, continuous). Stepwise backwards elimination was used to identify significant contributors. Additional details about stepwise model fit and collinearity are presented in Supplementary File 1. Since this is an exploratory study, only a simple correlation and not assessment of variance inflation factors were used to assess multicollinearity. No interaction term was a significant predictor of BRI or MI and were not included in the final model. $\mathrm{K}$-fold cross validation was used to validate model fit. $p$-values were chosen to select predicting variables. A $p$-value of 0.05 was considered significant and statistical analysis was performed using SAS 9.4 [31] (Supplementary File).

\section{Results}

A total of 27 retired NFL and NHL players contacted the research staff and were interested in participating in the study but 3 participants were not eligible because they could not perform the MRI ( 2 were unwilling due to claustrophobia and 1 was unable due to non-MRI compatible metallic implants) and 2 participants were unable to come to the research center for testing. Twenty-two participants signed the consent form but 1 participant was retrospectively excluded due to a serious brain injury from a motor vehicle accident that was only revealed after imaging. Hence, 21 participants made up the CS group with an average professional career length of 8.7 years. A total of 24 retired non-contact-sport controls contacted the research staff but 3 participants did not want to come to the research center for testing; hence, 21 participants made up the NS group. No participant in the NS group was unwilling/unable to receive an MRI. Participant demographics are presented in Table 1. CS and NS were matched on age and ethnicity, but CS had a significantly higher BMI than NS $(\mathrm{p}<0.001)$ and had fewer participants with college-level degrees or

\begin{tabular}{|c|c|c|c|}
\hline & $\begin{array}{l}\text { Non-Contact } \\
\text { Sports }(n=21)\end{array}$ & $\begin{array}{c}\text { Contact } \\
\text { Sports }(n=21)\end{array}$ & $p$-value \\
\hline Age in years, mean & $55.4 \pm 9.3$ & $56.7 \pm 9.5$ & 0.654 \\
\hline BMI in $\mathrm{kg} / \mathrm{m}^{2}$, mean & $24.5 \pm 2.5$ & $30.1 \pm 3.5$ & $<0.001$ \\
\hline Ethnicity & 21 Caucasians & $\begin{array}{c}19 \text { Caucasians, } \\
3 \text { African } \\
\text { American }\end{array}$ & 0.232 \\
\hline $\begin{array}{c}\text { Education, college degree, } \\
\mathrm{n}(\%)\end{array}$ & $19(90.5)$ & $10(47.6)$ & 0.024 \\
\hline MCI Diagnosis, n (\%) & $3(14)$ & $8(38)$ & 0.083 \\
\hline \multicolumn{4}{|l|}{ Sport, n (\%) } \\
\hline Football & - & $8(36.4)$ & \\
\hline Hockey & - & $14(63.6)$ & \\
\hline Running & $6(28.6)$ & - & \\
\hline Cycling & $6(28.6)$ & - & \\
\hline Triathlete & $2(9.5)$ & - & \\
\hline Track \& Field & $1(4.8)$ & - & \\
\hline History of smoking, n (\%) & $5(23.8)$ & $7(33.3)$ & 0.317 \\
\hline History of alcohol abuse, n (\%) & $1(4.8)$ & $6(28.6)$ & 0.093 \\
\hline History of drug abuse, $\mathrm{n}(\%)$ & $1(4.8)$ & $4(19.0)$ & 0.343 \\
\hline
\end{tabular}

Table 1: Participant demographics.

BMI: body mass index; MCI; mild cognitive impairment. higher ( $\mathrm{p}=0.024)$. Individual participant causes for chronic pain (defined as continuous pain for longer than 1-year), surgical history, list of replaced artificial body components, and results of cervical assessment are presented in Supplementary File 2. Eighty-one percent of CS ( $n=17)$ identified a source of chronic pain, with neck pain $(n=7)$ and headache $(n=5)$ being the most common. Nineteen percent of NS $(n=4)$ identified a source of chronic pain, which was significantly lower than CS $(\mathrm{p}<0.001)$ (Supplementary File).

\begin{tabular}{|c|c|c|c|}
\hline & $\begin{array}{l}\text { Non-Contact } \\
\text { Sports }(n=21)\end{array}$ & $\begin{array}{c}\text { Contact } \\
\text { Sports }(n=21)\end{array}$ & $p$-value \\
\hline \multicolumn{4}{|l|}{$\begin{array}{l}\text { How much did pain interfere with } \\
\text { your... }\end{array}$} \\
\hline ... day to day activities? & $1.24 \pm 0.62$ & $2.62 \pm 1.16$ & $<0.001$ \\
\hline $\begin{array}{l}\ldots \text { work around the } \\
\text { home? }\end{array}$ & $1.33 \pm 0.66$ & $2.38 \pm 1.12$ & 0.001 \\
\hline ... social activities? & $1.24 \pm 0.70$ & $2.24 \pm 1.26$ & 0.003 \\
\hline ... household chores? & $1.24 \pm 0.54$ & $2.24 \pm 1.09$ & 0.001 \\
\hline $\begin{array}{l}\ldots \text { things you do for } \\
\text { fun? }\end{array}$ & $1.24 \pm 0.54$ & $2.29 \pm 1.06$ & $<0.001$ \\
\hline $\begin{array}{l}\text {... enjoyment of social } \\
\text { activities? }\end{array}$ & $1.14 \pm 0.48$ & $2.19 \pm 1.12$ & $<0.001$ \\
\hline $\begin{array}{l}\text { Pain Interference total score } \\
\qquad(\max =30)\end{array}$ & $7.4 \pm 3.22$ & $13.95 \pm 6.30$ & $<0.001$ \\
\hline Pain Intensity (range 1-10) & $1.05 \pm 1.40$ & $3.91 \pm 2.63$ & $<0.001$ \\
\hline
\end{tabular}

Table 2: Pain Intensity and Pain Interference on PROMIS-43.

PROMIS-43: patient reported outcome measures information system.

\begin{tabular}{|c|c|c|c|}
\hline & $\begin{array}{l}\text { Non-Contact } \\
\text { Sports }(\mathrm{n}=21)\end{array}$ & $\begin{array}{c}\text { Contact Sports } \\
(n=21)\end{array}$ & $p$-value \\
\hline BDI-II total & $3.86 \pm 5.29$ & $10.19 \pm 8.05$ & 0.004 \\
\hline Category on BDI-II & & & 0.194 \\
\hline $\begin{array}{l}\text { Minimal Depres- } \\
\text { sion, } \mathrm{n}\end{array}$ & 20 & 15 & \multirow{4}{*}{-} \\
\hline Mild Depression, n & 1 & 3 & \\
\hline $\begin{array}{l}\text { Moderate Depres- } \\
\text { sion, } \mathrm{n}\end{array}$ & 0 & 2 & \\
\hline $\begin{array}{l}\text { Severe Depression, } \\
\mathrm{n}\end{array}$ & 0 & 1 & \\
\hline BAI total & $2.67 \pm 3.09$ & $6.10 \pm 6.17$ & 0.028 \\
\hline Category on BAI & & & 0.045 \\
\hline Minimal Anxiety, n & 19 & 12 & \multirow{4}{*}{ - } \\
\hline Mild Anxiety, n & 2 & 8 & \\
\hline Moderate Anxiety, n & 0 & 1 & \\
\hline Severe Anxiety, $\mathrm{n}$ & 0 & 0 & \\
\hline
\end{tabular}

Table 3: Depression (from BDI-II) and Anxiety (from BAI).

BDI-II: becks depression inventory-II; BAI: becks anxiety inventory.

Pain Intensity and Pain Interference values are presented in Table 2. CS group rated significantly greater interference $(p<0.001)$, due to pain in every activity, as well as significantly greater intensity $(\mathrm{p}<0.001)$ than NS group. Depression and anxiety scores are presented in Table 3. CS had significantly $(\mathrm{p}=0.004)$ higher raw depression scores on the BDI-II but were not significantly different $(\mathrm{p}=0.194)$ than NS in the incidence of mild to severe depression. CS also had significantly $(p=0.028)$ higher anxiety scores on the BAI, with a 
Citation: Haider MN, Antonius D, Cunningham A, Radick EJ, Leo RJ, et al. (2021) Case-Control Study Comparing the Relationship between Pain, Neurobehavioral Functioning and a History of Playing Professional Contact Sports. J Alzheimers Neurodegener Dis 7: 058.

\begin{tabular}{|c|c|c|c|}
\hline & $\begin{array}{c}\text { Non-Contact } \\
\text { Sports (n=21) }\end{array}$ & $\begin{array}{c}\text { Contact } \\
\text { Sports (n=21) }\end{array}$ & $\boldsymbol{p}$-value \\
\hline $\begin{array}{c}\text { Global Executive Function } \\
\text { composite score }\end{array}$ & $50.71 \pm 9.38$ & $58.24 \pm 11.82$ & $\mathbf{0 . 0 2 8}$ \\
\hline $\begin{array}{c}\text { Behavior Regulatory Index } \\
\text { T-Scores }\end{array}$ & $49.76 \pm 10.10$ & $56.86 \pm 13.41$ & 0.060 \\
\hline Inhibit & $51.57 \pm 8.53$ & $57.14 \pm 9.98$ & 0.059 \\
\hline Shift & $51.14 \pm 8.67$ & $56.67 \pm 10.49$ & 0.070 \\
\hline Emotional Control & $48.33 \pm 10.04$ & $54.43 \pm 14.33$ & 0.118 \\
\hline Self-Monitor & $48.24 \pm 9.18$ & $53.95 \pm 12.77$ & 0.104 \\
\hline $\begin{array}{c}\text { Abnormal Behavior Regulatory } \\
\text { Index, n (\%) }\end{array}$ & $6(28.6)$ & $2(9.5)$ & 0.116 \\
\hline Metacognitive Index T-Scores & $51.48 \pm 9.09$ & $58.52 \pm 10.82$ & $\mathbf{0 . 0 2 8}$ \\
\hline Initiate & $50.43 \pm 8.85$ & $57.48 \pm 11.22$ & $\mathbf{0 . 0 2 9}$ \\
\hline Working Memory & $52.38 \pm 11.84$ & $63.67 \pm 10.44$ & $\mathbf{0 . 0 0 2}$ \\
\hline Plan/Organize & $51.67 \pm 10.14$ & $56.81 \pm 11.13$ & 0.125 \\
\hline Task Monitor & $54.05 \pm 10.89$ & $57.05 \pm 10.30$ & 0.364 \\
\hline $\begin{array}{c}\text { Organization of } \\
\text { Materials }\end{array}$ & $49.48 \pm 8.13$ & $52.29 \pm 9.97$ & 0.314 \\
\hline $\begin{array}{c}\text { netacognitive Index, } \\
\text { n (\%) }\end{array}$ & $9(42.9)$ & $2(9.5)$ & $\mathbf{0 . 0 1 4}$ \\
\hline Abnormal
\end{tabular}

Table 4: Behavior Regulatory Index and Metacognitive Index T-scores from BRIEF-A.

BRIEF-A: behavior rating inventory of executive function - adult.

\begin{tabular}{|c|c|c|c|c|c|c|}
\hline Order & Effect & $\begin{array}{c}\text { Unadjusted } \\
\text { Parameter } \\
\text { Estimate } \\
\text { (SE) }\end{array}$ & $\begin{array}{c}\text { Adjusted } \\
\text { Parameter } \\
\text { Estimate } \\
\text { (SE) }\end{array}$ & $\begin{array}{l}\text { Adjusted } \\
\text { Wald } \\
\text { Statistic }\end{array}$ & $p$-value & Decision \\
\hline \multicolumn{7}{|c|}{ Predictors of Behavior Regulatory Index } \\
\hline & Intercept & $\begin{array}{c}161.4 \\
(102.3)\end{array}$ & $-10.5(6.1)$ & 2.92 & 0.087 & - \\
\hline 8 & $\begin{array}{c}\text { Pain } \\
\text { Intensity }\end{array}$ & $4.4(3.4)$ & - & 1.61 & 0.205 & Remove \\
\hline 7 & BDI-II & $43.6(27.4)$ & - & 1.33 & 0.248 & Remove \\
\hline 6 & $\begin{array}{l}\text { Educa- } \\
\text { tion }\end{array}$ & $21.8(12.9)$ & - & 0.81 & 0.369 & Remove \\
\hline 5 & $\begin{array}{c}\text { Contact } \\
\text { Sports }\end{array}$ & $-96.7(57.4)$ & - & 1.27 & 0.261 & Remove \\
\hline 4 & Age & $3.8(2.2)$ & - & 2.84 & 0.092 & Remove \\
\hline 3 & BMI & $4.5(2.7)$ & $0.48(0.23)$ & 4.28 & 0.039 & Keep \\
\hline 2 & $\begin{array}{l}\text { Pain } \\
\text { Interfer- } \\
\text { ence }\end{array}$ & $11.8(7.0)$ & $2.9(0.14)$ & 6.08 & 0.014 & Keep \\
\hline 1 & BAI & $152.5(88.7)$ & $5.0(1.9)$ & 6.69 & 0.010 & Keep \\
\hline \multicolumn{7}{|c|}{ Predictors of Metacognitive Index } \\
\hline & Intercept & $-24.6(296.8)$ & $4.1(1.1)$ & 13.27 & $<0.001$ & - \\
\hline 8 & BDI-II & $25.0(266.6)$ & - & 0.01 & 0.933 & Remove \\
\hline 7 & $\begin{array}{l}\text { Contact } \\
\text { Sports }\end{array}$ & $2.9(3.6)$ & - & 0.01 & 0.928 & Remove \\
\hline 6 & BMI & $-0.16(0.34)$ & - & 0.42 & 0.516 & Remove \\
\hline 5 & Age & $-0.20(0.15)$ & - & 0.53 & 0.465 & Remove \\
\hline 4 & $\begin{array}{c}\text { Pain } \\
\text { Intensity }\end{array}$ & $2.7(2.6)$ & - & 2.67 & 0.101 & Remove \\
\hline 3 & $\begin{array}{l}\text { Educa- } \\
\text { tion }\end{array}$ & $4.0(3.0)$ & - & 2.92 & 0.087 & Remove \\
\hline
\end{tabular}

\begin{tabular}{|c|c|c|c|c|c|c|}
\hline 2 & BAI & $8.7(7.0)$ & - & 3.09 & 0.078 & Remove \\
\hline 1 & $\begin{array}{c}\text { Pain } \\
\text { Interfer- } \\
\text { ence }\end{array}$ & $2.3(0.44)$ & $3.9(1.1)$ & 9.66 & 0.002 & Keep \\
\hline
\end{tabular}

Table 5: Results of stepwise backward elimination on general linear modeling used to predict Abnormal Behavior Regulatory Index and Metacognitive Index.

SE: standard error; BDI-II: becks depression inventory-II; BMI: body mass index; BAI: becks anxiety inventory.

significantly $(p=0.045)$ higher incidence of mild to severe anxiety than NS.

Executive function results obtained from the BRIEF-A are presented in Table 4. CS had significantly $(p=0.028)$ higher impairments in GEF composite score, and had significantly higher impairments in the MI composite score $(\mathrm{p}=0.028)$, initiate sub-category $(\mathrm{p}=0.029)$, and working memory sub-category $(\mathrm{p}=0.002)$. There were no significant differences in BRI composite score or BRI sub-category scores. BRIEF-A: behavior rating inventory of executive function - adult.

Results of fitting a model to predict BRI and MI are presented in Table 5. For BRI: education, interaction of pain intensity and interference, depression, pain intensity, history of playing contact sports, and age were removed step-by-step because they were not significant predictors of the final model. BMI $(\mathrm{p}=0.039)$, pain interference $(\mathrm{p}=0.014)$, and anxiety $(\mathrm{p}=0.010)$ were significant contributors to the model predicting BRI with $87.1 \%$ accuracy after cross-validation. For MI: education, interaction of pain intensity and interference, depression, age, history of contact sports, BMI, pain intensity, and anxiety were sequentially removed because they were not significant predictors. Only pain interference was a significant $(\mathrm{p}=0.002)$ contributor to the model predicting MI with $75.7 \%$ accuracy after cross-validation.

\section{Discussion}

We found that retired NFL and NHL athletes report being in more chronic pain than age-matched retired, non-contact sport master athletes and that it interfered significantly with their daily activities. These retired contact sport athletes also identified more causes of chronic pain and had more orthopedic surgeries, such as joint replacements, than non-contact sport controls. We found that pain interference, but not pain intensity, was a significant predictor of impairments in behavior regulation and metacognition in retired professional contact sport athletes. Behavior regulation and metacognition are two important components of executive functioning. These data suggest that early decline in neurobehavioral functioning in retired contact-sport athletes may have causes other than a history of playing contact sports, with their attendant risk of sustaining repetitive head impacts. Our control group was more physically active, healthy, and more educated, which could account for the differences in depression, anxiety, and executive functioning when compared with the contact sport athletes. Nevertheless, pain interference remained a strong predictor of both behavioral regulation and metacognition even in the presence of depression and anxiety, which are themselves components of executive functioning. Moreover, pain itself is able to propagate anxiety via several mechanisms, ${ }^{32}$ which could explain why both pain interference and anxiety contributed to both models. Companion studies published from the Healthy Ageing Mind project [26] also found that history of playing contact sports was not associated with advanced brain imaging abnormalities [33], abnormal psychometric 
Citation: Haider MN, Antonius D, Cunningham A, Radick EJ, Leo RJ, et al. (2021) Case-Control Study Comparing the Relationship between Pain, Neurobehavioral Functioning and a History of Playing Professional Contact Sports. J Alzheimers Neurodegener Dis 7: 058.

assessments [10], or presence of MCI [11]. The conclusion from those studies was that retired contact sport athletes were functioning at a level consistent with their age and education.

Professional contact-sport athletes train vigorously and often sustain orthopedic injuries, resulting in several sources of chronic pain and/or disability throughout their lives [18]. The sensory and emotional experience of pain, and its deleterious impact on mental health and cognitive functioning, could contribute to early neurocognitive decline. Increased pain intensity has been linked to impaired attention, psychomotor speed, executive functioning [34], and working memory [35], all of which are risk factors for MCI. Chronic pain has also been linked to chronic neuroinflammation in the brain [36] and maladaptive neuroplasticity [37]. Chronic pain may also lead to maladaptive coping mechanisms or substance abuse, further affecting neurocognitive functioning. Our contact sport group had a greater incidence of alcohol abuse, which was close to being statistically significant ( $\mathrm{p}=0.09$ ). Additionally, chronic pain has been shown to cause structural changes in the brain $[38,39]$. A study using advanced imaging found that chronic pain remodels grey matter (GM) density in specific regions of the somatosensory, motor and prefrontal cortices [40]. These alterations varied according to the site of the pain; for example, back or arthritic pain, but the common finding was a significant reduction in insular GM density, which correlated in one study with the duration of chronic pain [37]. The insula, a region deep in the cerebral cortex, is crucial for working memory [41] and emotion control [42]. Future TES research in contact sport athletes, and its linkage to CTE pathology, should account for the effect of chronic pain on cognitive and emotional functioning

\section{Limitations}

Our study has a number of limitations. We were unable to ascertain with any degree of confidence the actual number of repetitive head impacts and concussions in the retired NFL and NHL athletes. All contact sport participants reported a history of numerous concussions, but some of the reports (e.g. "more than a thousand") were illogical and there was no way to confirm them. The average career length was 8.7 years, which is a substantial amount of time to accumulate blows to the head. Also, professional years played does not account for the years of contact and potential head injuries sustained during high school and college, nor does it account for activities after retirement. Hence our study is only able to compare the risk of neurocognitive decline and a history of playing contact sports rather than a history of repetitive head injuries. Our results should be interpreted in this context. The contact sport group also showed a greater interest in the results of their neurocognitive testing, and were disappointed when their self-reported deficiencies in neurocognitive function were not verified on objective testing performed by a neuropsychologist. Control group participants on the other hand were not interested in their neurocognitive testing results, implying that contact sport participants were more concerned about the main outcome variable (early neurocognitive decline), which may have affected the results.

The control group consisted of master athletes who had retired from competition but continued to be physically active. This resulted in a control group that had lower BMI, higher education, and better health in general. While subject to selection bias, this control group should have maximized differences with the retired contact sport group and reduced the possibility of a Type-II error. Nevertheless, we did not find any significant differences in cognition/behavior between the two groups. Higher BMI in the contact sport group could also contribute to its higher incidence of joint and back pain/surgeries and higher pain scores, which is another major confounder. Future studies should select a control group matched for BMI and from non-contact or limited-contact team sports.

Finally, another possible confounder is headache as a source of chronic pain. Repetitive head injuries are associated with chronic headaches, which could cause more chronic pain and risk for earlier neurocognitive decline. Contact sport participants reported headache as a source of chronic pain more often than the non-contact participants ( 5 versus 2 ) but this was not significant. Still, the findings from our study should be placed in context of this possible confounder.

\section{Conclusion}

Retired contact sport athletes are at risk of early neurocognitive decline, which is suspected to be primarily due to repetitive head injuries received throughout their careers. There may, however, be other factors that cause or contribute to cognitive and emotional decline, including chronic pain. In our study, retired NFL and NHL athletes reported more chronic pain that interfered with daily activities than age-matched non-contact sport athletes. Pain interference, as opposed to a history of playing contact sport, contributed significantly to impairment in two key components of executive functioning: behavior regulation and metacognition. Our results suggest that future research on behavioral and cognitive decline in aging athletes should account for their experience of chronic pain.

\section{Supplimentry Files}

https://www.heraldopenaccess.us//fulltext/Alzheimers- \&-Neurodegenerative-Diseases/Supplementary-File.docx

\section{References}

1. McKee AC, Stein TD, Nowinski CJ, Stein TD, Alvarez EV, et al. (2012) The spectrum of disease in chronic traumatic encephalopathy. Brain 136: 43-64.

2. Gardner RC, Yaffe K (2015) Epidemiology of mild traumatic brain injury and neurodegenerative disease. Molecular and Cellular Neuroscience 66: $75-80$.

3. Broglio SP, Eckner JT, Paulson HL, Kutcher JS (2012) Cognitive decline and aging: The role of concussive and subconcussive impacts. Exercise and Sport Sciences Reviews 40: 138-144.

4. Maroon JC, Winkelman R, Bost J, Amos A, Mathyssek C, et al. (2015) Chronic traumatic encephalopathy in contact sports: A systematic review of all reported pathological cases. PloS One10: e0117338.

5. Mez J, Daneshvar DH, Kiernan PT, Abdolmohammadi B, Alvarez VE, et al. (2017) Clinicopathological evaluation of chronic traumatic encephalopathy in players of American football. Jama 318: 360-370.

6. Gavett BE, Stern RA, McKee AC (2011) Chronic traumatic encephalopathy: A potential late effect of sport-related concussive and subconcussive head trauma. Clinics in Sports Medicine 30: 179-188.

7. Alosco M, Kasimis A, Stamm J, Chua AS, Baugh CM, et al. (2017) Age of first exposure to American football and long-term neuropsychiatric and cognitive outcomes. Translational Psychiatry 7: e1236-e1236.

8. Esopenko C, Chow TW, Tartaglia MC, Bacopulas A, Kumar P, et al. (2017) Cognitive and psychosocial function in retired professional hockey players. J Neurol Neurosurg Psychiatry 88: 512-519.

9. McMillan T, McSkimming P, Wainman-Lefley J, Maclean LM, Connachie AM, et al. (2017) Long-term health outcomes after exposure to repeated concussion in elite level: Rugby union players. Journal of Neurology, Neurosurgery \& Psychiatry 88: 505-511. 
Citation: Haider MN, Antonius D, Cunningham A, Radick EJ, Leo RJ, et al. (2021) Case-Control Study Comparing the Relationship between Pain, Neurobehavioral Functioning and a History of Playing Professional Contact Sports. J Alzheimers Neurodegener Dis 7: 058.

10. Willer BS, Tiso MR, Haider MN, Hinds AL, Baker JG, et al. (2018) Evaluation of executive function and mental health in retired contact sport athletes. The Journal of Head Trauma Rehabilitation 33: E9-E15.

11. Baker JG, Leddy JJ, Hinds AL, Haider MN, Shucard J, et al. (2018) An exploratory study of mild cognitive impairment of retired professional contact sport athletes. The Journal of head trauma rehabilitation 33: E16-E23.

12. Willeumier K, Taylor D, Amen D (2012) Elevated body mass in National Football League players linked to cognitive impairment and decreased prefrontal cortex and temporal pole activity. Translational Psychiatry 2: e68.

13. Churchill TW, Krishnan S, Weisskopf M, Yates BA, Speizer FE, et al (2018) Weight gain and health affliction among former National Football League players. The American Journal of Medicine 131: 1491-1498.

14. Morris TP, McCracken C, Baggish A, Zafonte R, Taylor HA, et al. (2019) Multisystem afflictions in former National Football League players. American Journal of Industrial Medicine 62: 655-662.

15. Hart J, Kraut MA, Womack KB, Strain J, Didehbani N, et al. (2013) Neuroimaging of cognitive dysfunction and depression in aging retired $\mathrm{Na}$ tional Football League players: A cross-sectional study. JAMA Neurology 70: 326-335.

16. Haider MN, ODonnell K, Bezherano I, Horvath PJ, Leddy JJ, et al. (2019) Retired Professional Contact Sport Athletes are more sedentary and consume fewer brain healthy nutrients than Non-contact Sport Controls. JSM Sports Medicine and Research 3: 8 .

17. Woods C, Hawkins R, Maltby S, Hulse M, Thomas A, et al. (2004) The Football Association Medical Research Programme: An audit of injuries in professional football-analysis of hamstring injuries. British Journal of Sports Medicine 38: 36-41.

18. Murray TA, Cook TD, Werner SL, Schlegel TF, Hawkins RJ (2001) The effects of extended play on professional baseball pitchers. The American Journal of Sports Medicine 29: 137-142.

19. Schwenk TL, Gorenflo DW, Dopp RR, Hipple E (2007) Depression and pain in retired professional football players. Medicine \& Science in Sports \& Exercise 39: 599-605.

20. Cottler LB, Abdallah AB, Cummings SM, Barr J, Banks R, et al. (2011) Injury, pain, and prescription opioid use among former National Football League (NFL) players. Drug and Alcohol Dependence 116: 188-194.

21. Higgins DM, Martin AM, Baker DG, Vasterling JJ, Risbrough V (2018) The Relationship Between Chronic Pain and Neurocognitive Function: A Systematic Review. The Clinical Journal of Pain 34: 262-275.

22. Williams L, Jones W, Shen J, Robinson R, Weinberger M, et al. (2003) Prevalence and impact of depression and pain in neurology outpatients. Journal of Neurology, Neurosurgery \& Psychiatry 74: 1587-1589.

23. Jamison RN, Sbrocco T, Parris WC (1989) The influence of problems with concentration and memory on emotional distress and daily activities in chronic pain patients. The International Journal of Psychiatry in Medicine 18: 183-191.

24. Osborne TL, Jensen MP, Ehde DM, Hanley MA, Kraft G (2007) Psychosocial factors associated with pain intensity, pain-related interference, and psychological functioning in persons with multiple sclerosis and pain. Pain 127: 52-62.

25. Jak AJ, Bondi MW, Delano-Wood L, Wierenga C, Corey-Bloom J, et al. (2009) Quantification of five neuropsychological approaches to defining mild cognitive impairment. The American Journal of Geriatric Psychiatry 17: 368-375.
26. Willer BS, Zivadinov R, Haider MN, Miecznikowski JC, Leddy JJ (2018) A preliminary study of early-onset dementia of former professional football and hockey players. The Journal of Head Trauma Rehabilitation 33: E1-E8.

27. Roth RM, Gioia GA (2005) Behavior rating inventory of executive function--adult version. Psychological Assessment Resources.

28. DeWalt DA, Rothrock N, Yount S, Stone AA (2007) Evaluation of item candidates: the PROMIS qualitative item review. Medical Care 45: S12-S21.

29. Beck AT, Steer RA, Brown GK (1996) Beck depression inventory-II. San Antonio 78: 490-498.

30. Beck AT, Epstein N, Brown G, Steer RA (1988) An inventory for measuring clinical anxiety: Psychometric properties. Journal of Consulting and Clinical Psychology 56: 893-897.

31.https://citeseerx.ist.psu.edu/viewdoc/download?doi $=10.1 .1 .359 .9844 \&$ rep $=$ rep $1 \&$ type $=$ pdf

32. Zhuo M (2016) Neural mechanisms underlying anxiety-chronic pain interactions. Trends in Neurosciences 39: 136-145.

33. Zivadinov R, Polak P, Schweser F, Bergsland N, Hagemeier J, et al. (2018) Multimodal imaging of retired professional contact sport athletes does not provide evidence of structural and functional brain damage. The Journal of head trauma rehabilitation 33: E24-E32.

34. Tamburin S, Maier A, Schiff S, Lauriola MF, Rosa ED, et al. (2014) Cognition and emotional decision-making in chronic low back pain: An ERPs study during Iowa gambling task. Frontiers in Psychology 5: 1350.

35. Berryman C, Stanton TR, Bowering KJ, Tabor A, McFarlane A, et al. (2013) Evidence for working memory deficits in chronic pain: A systematic review and meta-analysis. Pain 154: 1181-1196.

36. Ji RR, Nackley A, Huh Y, Terrando N, Maixner W (2018) Neuroinflammation and central sensitization in chronic and widespread pain. Anesthesiology 129: 343-366.

37. Apkarian AV, Hashmi JA, Baliki MN (2011) Pain and the brain: Specificity and plasticity of the brain in clinical chronic pain. Pain 152: S49-S64.

38. Oosterman J, Gibson S, Pulles W, Veldhuijzen D (2013) On the moderating role of age in the relationship between pain and cognition. European Journal of Pain 17: 735-741.

39. Lee D, Pendleton N, Tajar A, O’Neill TW, O’Connor DB, et al. (2010) Chronic widespread pain is associated with slower cognitive processing speed in middle-aged and older European men. Pain 151:30-36.

40. Ung H, Brown JE, Johnson KA, Younger J, Hush J, et al. (2014) Multivariate classification of structural MRI data detects chronic low back pain. Cerebral Cortex 24: 1037-1044.

41. Menon DK, Schwab K, Wright DW, Maas AI (2010) Position statement: Definition of traumatic brain injury. Archives of Physical Medicine and Rehabilitation 91: 1637-1640.

42. Elman I, Borsook D (2016) Common brain mechanisms of chronic pain and addiction. Neuron 89: 11-36. 


\section{$\mathrm{H}$ \\ maxno}

Advances In Industrial Biotechnology | ISSN: 2639-5665

Advances In Microbiology Research | ISSN: 2689-694X

Archives Of Surgery And Surgical Education | ISSN: 2689-3126

Archives Of Urology

Archives Of Zoological Studies | ISSN: 2640-7779

Current Trends Medical And Biological Engineering

International Journal Of Case Reports And Therapeutic Studies | ISSN: 2689-310X

Journal Of Addiction \& Addictive Disorders | ISSN: 2578-7276

Journal Of Agronomy \& Agricultural Science | ISSN: 2689-8292

Journal Of AIDS Clinical Research \& STDs | ISSN: 2572-7370

Journal Of Alcoholism Drug Abuse \& Substance Dependence | ISSN: 2572-9594

Journal Of Allergy Disorders \& Therapy | ISSN: 2470-749X

Journal Of Alternative Complementary \& Integrative Medicine | ISSN: 2470-7562

Journal Of Alzheimers \& Neurodegenerative Diseases | ISSN: 2572-9608

Journal Of Anesthesia \& Clinical Care | ISSN: 2378-8879

Journal Of Angiology \& Vascular Surgery | ISSN: 2572-7397

Journal Of Animal Research \& Veterinary Science | ISSN: 2639-3751

Journal Of Aquaculture \& Fisheries | ISSN: 2576-5523

Journal Of Atmospheric \& Earth Sciences | ISSN: 2689-8780

Journal Of Biotech Research \& Biochemistry

Journal Of Brain \& Neuroscience Research

Journal Of Cancer Biology \& Treatment | ISSN: 2470-7546

Journal Of Cardiology Study \& Research | ISSN: 2640-768X

Journal Of Cell Biology \& Cell Metabolism | ISSN: 2381-1943

Journal Of Clinical Dermatology \& Therapy | ISSN: 2378-8771

Journal Of Clinical Immunology \& Immunotherapy | ISSN: 2378-8844

Journal Of Clinical Studies \& Medical Case Reports | ISSN: 2378-8801

Journal Of Community Medicine \& Public Health Care | ISSN: 2381-1978

Journal Of Cytology \& Tissue Biology | ISSN: 2378-9107

Journal Of Dairy Research \& Technology | ISSN: 2688-9315

Journal Of Dentistry Oral Health \& Cosmesis | ISSN: 2473-6783

Journal Of Diabetes \& Metabolic Disorders | ISSN: 2381-201X

Journal Of Emergency Medicine Trauma \& Surgical Care | ISSN: 2378-8798

Journal Of Environmental Science Current Research | ISSN: 2643-5020

Journal Of Food Science \& Nutrition | ISSN: 2470-1076

Journal Of Forensic Legal \& Investigative Sciences | ISSN: 2473-733X

Journal Of Gastroenterology \& Hepatology Research | ISSN: 2574-2566
Journal Of Genetics \& Genomic Sciences | ISSN: 2574-2485

Journal Of Gerontology \& Geriatric Medicine | ISSN: 2381-8662

Journal Of Hematology Blood Transfusion \& Disorders | ISSN: 2572-2999

Journal Of Hospice \& Palliative Medical Care

Journal Of Human Endocrinology | ISSN: 2572-9640

Journal Of Infectious \& Non Infectious Diseases | ISSN: 2381-8654

Journal Of Internal Medicine \& Primary Healthcare | ISSN: 2574-2493

Journal Of Light \& Laser Current Trends

Journal Of Medicine Study \& Research | ISSN: 2639-5657

Journal Of Modern Chemical Sciences

Journal Of Nanotechnology Nanomedicine \& Nanobiotechnology | ISSN: 2381-2044

Journal Of Neonatology \& Clinical Pediatrics | ISSN: 2378-878X

Journal Of Nephrology \& Renal Therapy | ISSN: 2473-7313

Journal Of Non Invasive Vascular Investigation | ISSN: 2572-7400

Journal Of Nuclear Medicine Radiology \& Radiation Therapy | ISSN: 2572-7419

Journal Of Obesity \& Weight Loss | ISSN: 2473-7372

Journal Of Ophthalmology \& Clinical Research | ISSN: 2378-8887

Journal Of Orthopedic Research \& Physiotherapy | ISSN: 2381-2052

Journal Of Otolaryngology Head \& Neck Surgery | ISSN: 2573-010X

Journal Of Pathology Clinical \& Medical Research

Journal Of Pharmacology Pharmaceutics \& Pharmacovigilance | ISSN: 2639-5649

Journal Of Physical Medicine Rehabilitation \& Disabilities | ISSN: 2381-8670

Journal Of Plant Science Current Research | ISSN: 2639-3743

Journal Of Practical \& Professional Nursing | ISSN: 2639-5681

Journal Of Protein Research \& Bioinformatics

Journal Of Psychiatry Depression \& Anxiety | ISSN: 2573-0150

Journal Of Pulmonary Medicine \& Respiratory Research | ISSN: 2573-0177

Journal Of Reproductive Medicine Gynaecology \& Obstetrics | ISSN: 2574-2574

Journal Of Stem Cells Research Development \& Therapy | ISSN: 2381-2060

Journal Of Surgery Current Trends \& Innovations | ISSN: 2578-7284

Journal Of Toxicology Current Research | ISSN: 2639-3735

Journal Of Translational Science And Research

Journal Of Vaccines Research \& Vaccination | ISSN: 2573-0193

Journal Of Virology \& Antivirals

Sports Medicine And Injury Care Journal | ISSN: 2689-8829

Trends In Anatomy \& Physiology | ISSN: 2640-7752

Submit Your Manuscript: https://www.heraldopenaccess.us/submit-manuscript 